\title{
Electroless Nanoparticle Film Deposition Compatible with Photolithography, Microcontact Printing, and Dip-Pen Nanolithography Patterning Technologies
}

2002

Vol. 2, No. 12

1369-1372

\author{
Lon A. Porter, Jr., Hee Cheul Choi, J. M. Schmeltzer, Alexander E. Ribbe, \\ Lindsay C. C. Elliott, and Jillian M. Buriak* \\ Department of Chemistry, 1393 Brown Laboratories of Chemistry, Purdue University, \\ West Lafayette, Indiana 47907-1393
}

Received September 12, 2002; Revised Manuscript Received October 14, 2002

\begin{abstract}
Nanoparticles of $\mathrm{Au}, \mathrm{Pd}$, and $\mathrm{Pt}$ form spontaneously as thin, morphologically complex metallic films upon various semiconducting or metal substrates such as $\mathrm{Ge}(100), \mathrm{Cu}, \mathrm{Zn}$, and $\mathrm{Sn}$, via galvanic displacement from aqueous metal salt solutions. Patterning of these high surface area metal films into ordered structures utilizing photolithography, microcontact printing $(\mu-C P)$, and dip-pen nanolithography (DPN) is demonstrated on flat $\mathrm{Ge}(100)$, and (for $\mu$ - $\mathrm{CP}$ ) on rough $\mathrm{Zn}$ foil.
\end{abstract}

There is presently enormous interest in patterning surfaces with micro- and nanometer resolution for both fundamental investigations and technological applications. ${ }^{1}$ Recent developments, such as dip-pen nanolithography (DPN) ${ }^{2}$ and microcontact printing $(\mu-\mathrm{CP}),{ }^{1}$ employ a liquid-phase "ink" to pattern a solid "paper" substrate. Established inks for DPN and $\mu$-CP include thiols, ${ }^{2}$ DNA, ${ }^{3}$ polymers, ${ }^{4}$ proteins, ${ }^{5,6}$ hexamethyldisilazane, ${ }^{7}$ alkylsiloxanes, ${ }^{8}$ palladium colloids, ${ }^{9}$ sols (Al, Si, Sn oxides), ${ }^{10}$ metal complexes,${ }^{11}$ and gold. ${ }^{12}$ In this paper, we demonstrate that $\mathrm{Au}, \mathrm{Pd}$, and Pt nanoparticle films, produced through a spontaneous electroless deposition reaction, are amenable to patterning via photolithography, $\mu$-CP, and DPN. Because many properties of the $\mathrm{Au}, \mathrm{Pd}$, and Pt nanoparticle films, including film thickness, particle size, and roughness, can be controlled, ${ }^{13}$ they are of importance for the interfacing of nanoparticles with metals and semiconductors, ${ }^{14-16}$ the development of high surface area catalysts, ${ }^{17}$ SERS,${ }^{18}$ and other applications. ${ }^{19}$ Examples of thin, well adhering nanoparticle films prepared via immersion of $\mathrm{Ge}(100)$ and metal substrates into dilute, aqueous solutions of $\mathrm{AuCl}_{4}{ }^{-}, \mathrm{PdCl}_{4}{ }^{2-}$, or $\mathrm{PtCl}_{4}{ }^{2-}$ salts are shown in Figure 1. Deposition proceeds via galvanic displacement ${ }^{20}$ in the absence of fluoride, $\mathrm{pH}$ buffers, complexing agents, or external reducing agents, in contrast to earlier work. ${ }^{21-30}$ Patterning of these particle film as-

\footnotetext{
* Corresponding author. E-mail: buriak@purdue.edu
}

semblies is essential for their subsequent incorporation into higher order architectures and devices. ${ }^{31,32}$

The first patterning motif tested, photolithography, was carried out as outlined in Figure 2a. Approximately $0.1 \mathrm{~mL}$ of neat dodecene was applied to a $1 \mathrm{~cm}^{2}$ hydride-terminated $\mathrm{Ge}(100)$ surface, which was subequently exposed to $254 \mathrm{~nm}$ UV light ( $9 \mathrm{~mW} \mathrm{~cm}^{-2}$ intensity) through a metal grid contact mask under an inert atmosphere. ${ }^{33}$ The illuminated regions undergo hydrogermylation at room temperature within thirty minutes. A related functionalization approach has been shown on silicon. ${ }^{34}$ This leads to spatially defined 5-25 $\mu \mathrm{m}$ sized domains of dodecyl and hydride. Immersion of the hydride/alkyl surface into aqueous noble metal salt solutions results in preferential deposition in the hydride areas since the alkyl monolayer functions as an effective dielectric barrier (Figure 3). The hydride surface oxidizes in-situ and subsequently dissolves in the aqueous medium. Metal salt reduction and deposition can then occur, leading to metallization between the alkylated domains. In this case, the germanium oxide dissolves in water, ${ }^{35}$ leading to intimate electrical contact between the semiconductor bulk and the metal salts and affording a faster rate of deposition. In the case of silicon, however, this approach is not feasible because the native oxide has been shown to effectively prevent metal deposition due to its insolubility in water. ${ }^{20}$ Attempts to use spatially defined regions of hydride/oxide to drive patterned metal deposition were partially successful, but the similar deposi- 

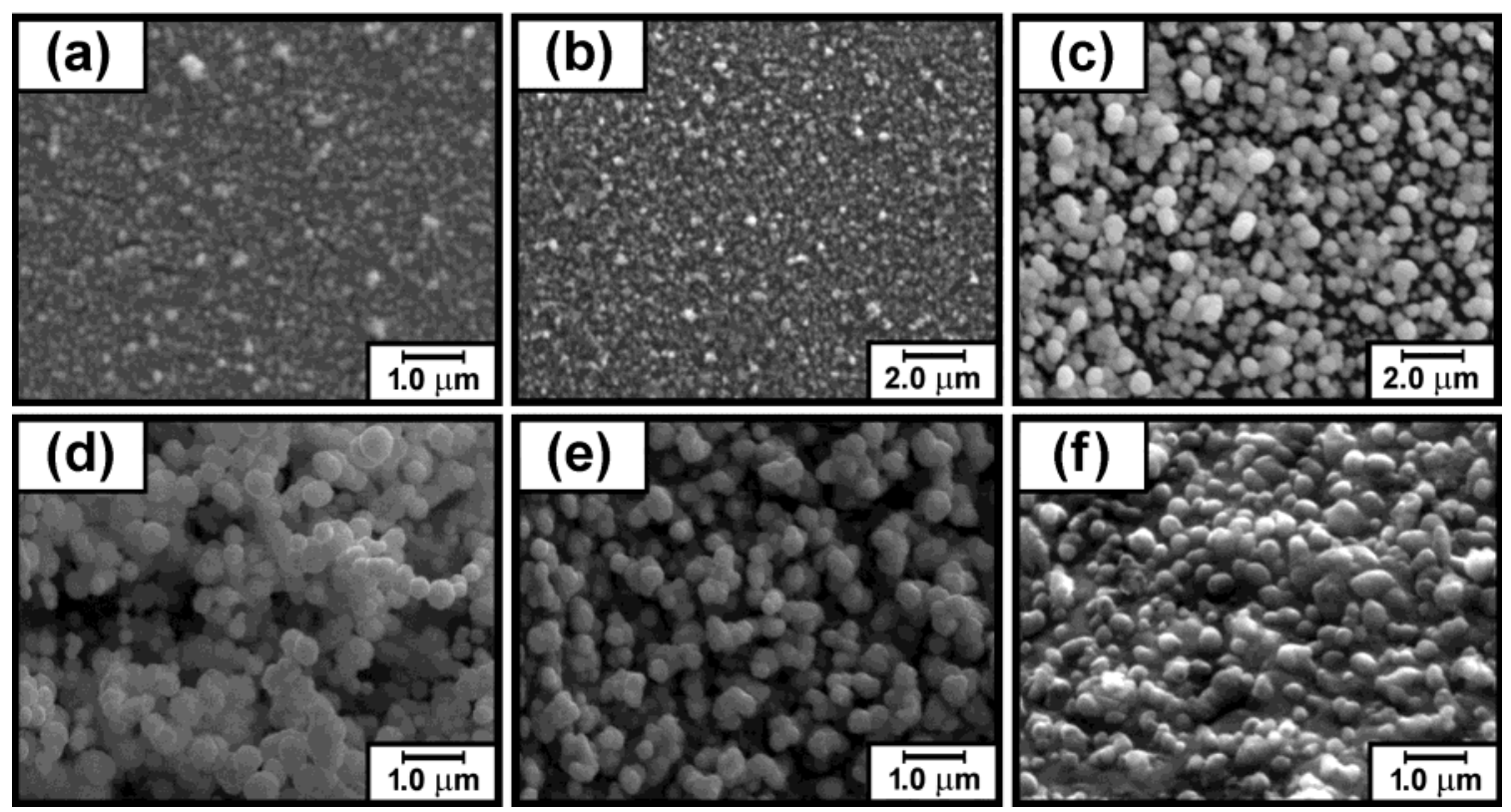

Figure 1. SEM images of (a) an Au nanoparticle film deposited spontaneously in 90 min on a Ge(100) surface from a $1 \mathrm{mM}$ aqueous $\mathrm{AuCl}_{4}{ }^{-}$solution; (b) $\mathrm{Pd}$ and (c) $\mathrm{Pt}$ on a Ge(100) surface, formed from aqueous $1 \mathrm{mM} \mathrm{PdCl}_{4}{ }^{2-}$ and $\mathrm{PtCl}_{4}{ }^{2-}$ for $120 \mathrm{~min}$; Pt films on (d) $\mathrm{Zn}$

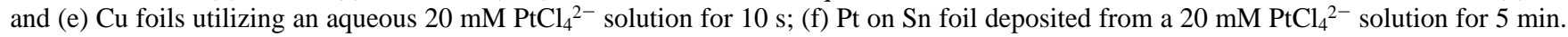

\section{(a) Photolithography}

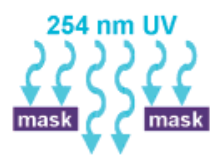

(H) Ge Substrate

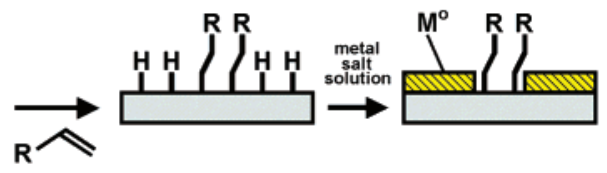

(b) Microcontact Printing ( $\mu-\mathrm{CP})$

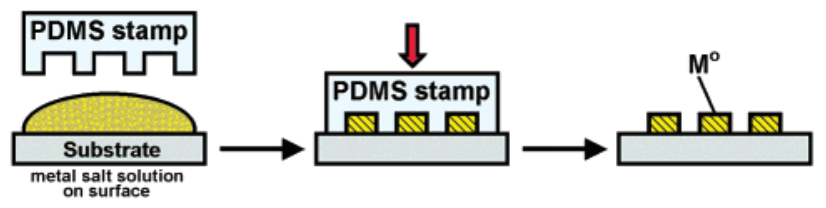

(c) Dip-pen Nanolithography (DPN)

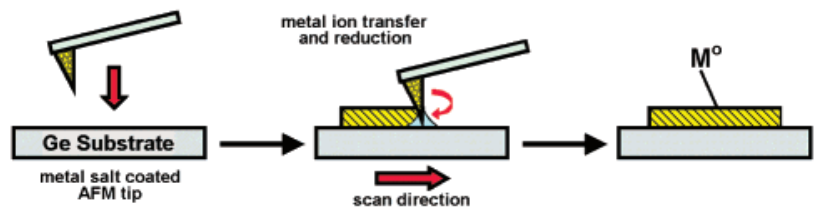

Figure 2. Outline of the three patterning approaches investigated: (a) photolithography, (b) microcontact printing ( $\mu$-CP), and (c) dippen nanolithography (DPN).

tion rates on the two interfaces did not lead to adequate selectivity (see Supporting Information).

Contact methods were then attempted to yield micro- and nanosized features on surfaces (Figure $2 b$ ). $\mu$-CP is shown to pattern noble metal deposition on germanium using both hydrophobic and hydrophilic polydimethoxysilane (PDMS) stamps. Negative patterning yields highly regular, micronscale deposition on $\mathrm{Ge}(100)$. Because $\mathrm{PdCl}_{4}{ }^{2-}$ is reduced only
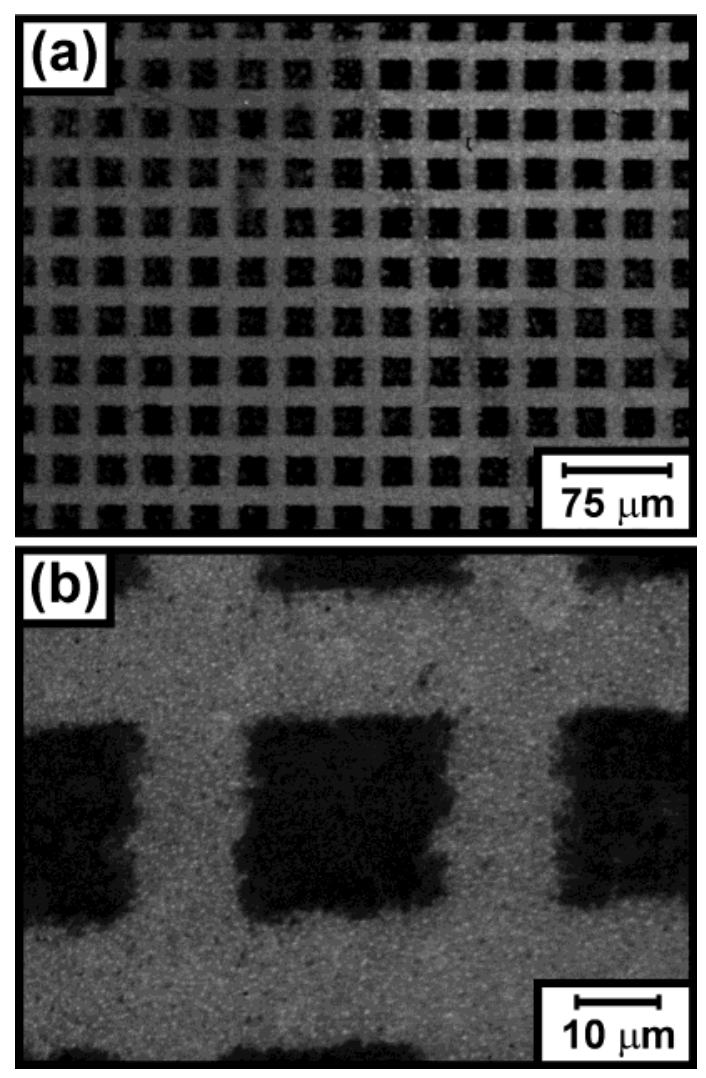

Figure 3. Scanning electron micrographs of photopatterned deposition of Pd upon a $\mathrm{Ge}(100)$ surface. Hydrogermylation of 1-dodecene by the $\mathrm{Ge}(100)-\mathrm{H}_{x}$ surface, mediated by UV light in the unmasked areas results in dodecyl termination in the square regions; the grid lines remain hydride terminated. The organic monolayers act as an effective ultrathin resist and immersion in aqueous $2 \mathrm{mM}$ aqueous $\mathrm{PdCl}_{4}{ }^{2-}$ for $30 \mathrm{~s}$ results in selective deposition within the hydride-terminated grid lines.

slowly on the germanium oxide interface, the solution was dropped upon the surface and was immediately pressed with 

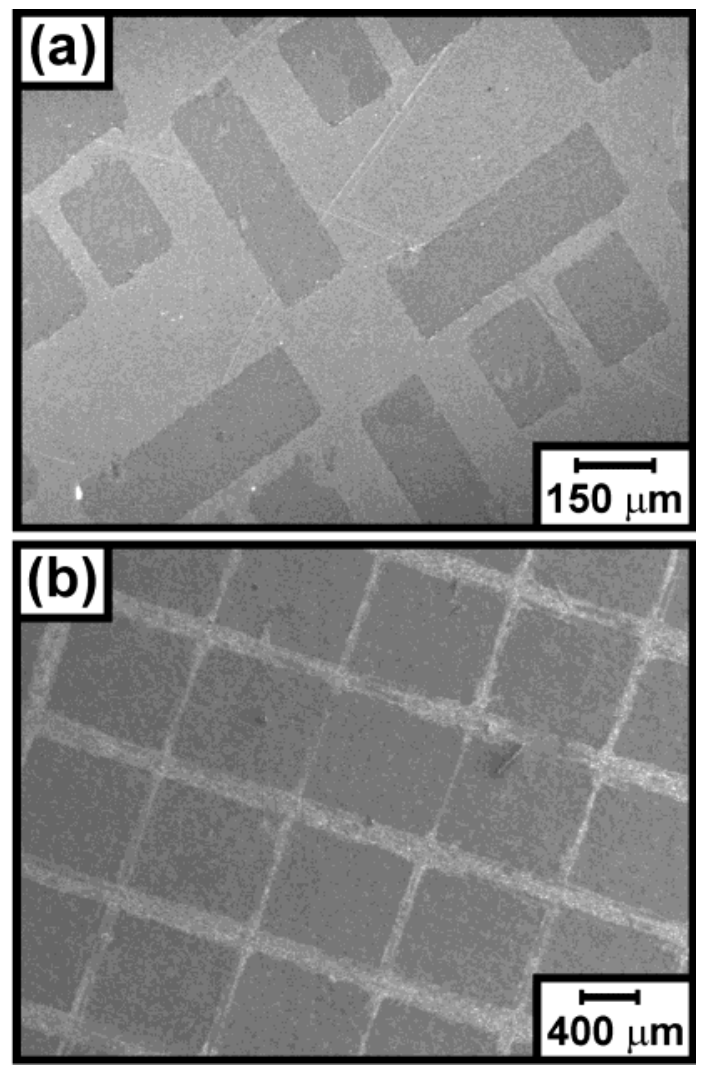

Figure 4. (a) Scanning electron micrograph of a negatively $\mu$-CP patterned $\mathrm{Ge}(100)$ surface with a $2 \mathrm{mM}$ aqueous $\mathrm{PdCl}_{4}{ }^{2-}$ solution. The bright areas represent areas of Pd deposition, whereas the dark areas represent unreacted Ge. (b) SEM image of a negatively $\mu$-CP patterned $\mathrm{Zn}$ foil with a $2 \mathrm{mM}$ aqueous solution of $\mathrm{PtCl}_{4}{ }^{2-}$ for 30 $\mathrm{s}$. The dark areas are unreacted $\mathrm{Zn}$, and the light lines, the deposited Pt.

an oxidized, hydrophilic PDMS stamp. Light pressure was applied to push excess aqueous metal salt solution from the stamped interface. After 10 minutes, the stamp was removed and the germanium was immediately rinsed with deionized water to yield negative patterning with a spatially defined resolution on the order of $40 \mu \mathrm{m}$ (Figure $4 \mathrm{a}$ ). To further demonstrate the versatility of $\mu$-CP, negative patterning was carried out on zinc foil with an aqueous $\mathrm{PtCl}_{4}{ }^{2-}$ ink using a hydrophobic, untreated PDMS stamp. The foil roughness is clearly visible by SEM and was not pretreated in any way to reduce or flatten the material. Micron-scale lines of the deposited platinum metal film can be clearly observed, despite the surface roughness (Figure $4 \mathrm{~b}$ ). Consequently, this technique is not limited to flat surfaces and can be extended to morphologically inhomogeneous interfaces.

DPN, outlined in Figure 2c, was demonstrated through the writing of a $0.55 \mu \mathrm{m}$ long gold line with a width of 30 $\mathrm{nm}$ and height of $10 \mathrm{~nm}$ through the spontaneous electroless deposition of $\mathrm{AuCl}_{4}{ }^{-}$, delivered via the AFM tip, upon an untreated $\mathrm{Ge}(100)$ wafer (Figure 5). In a typical experiment, a silicon tip was dipped in an aqueous $20 \mathrm{mM} \mathrm{AuCl}_{4}{ }^{-}$ solution, diluted with acetonitrile $(1: 10 \mathrm{v} / \mathrm{v})$ to reduce surface tension, and dried for $5 \mathrm{~min}$. Writing was accomplished at a rate of $0.2 \mu \mathrm{m} / \mathrm{s}$ in a constant humidity environment of $50 \%$. Similar results were obtained with $\mathrm{PdCl}_{4}{ }^{2-}$.

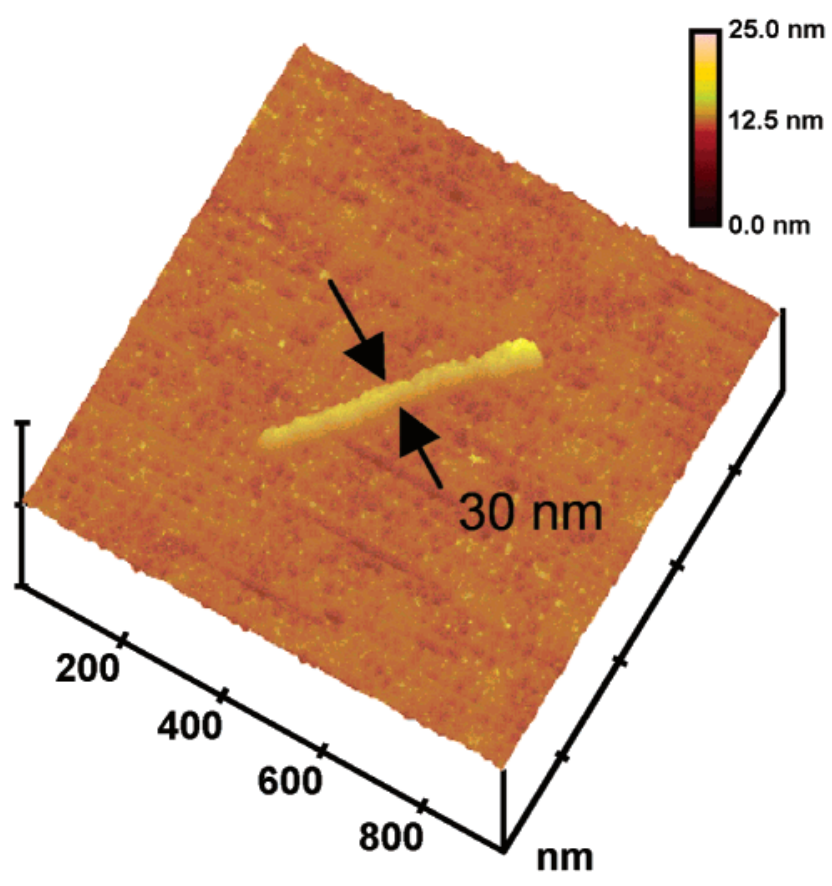

Figure 5. Au line (550 nm long, $30 \mathrm{~nm}$ wide, $10 \mathrm{~nm}$ in height) drawn in air through DPN of a native oxide coated Ge(100) surface.

In conclusion, electroless deposition of noble metal salts on semiconducting and metallic substrates leads to morphologically complex, nanostructured films that can be patterned through photolithography, $\mu$-CP, and DPN. The extent to which these techniques are useful for the patterning of other paper and ink combinations is being established. The molecular contact between the metal particles and the underlying substrate is presently under investigation to determine their use as nanoscale electrical contacts for interfacing a range of different organic and biomolecules and for catalytic and sensor applications, among others.

Acknowledgment. We gratefully acknowledge support from NSF for grants CHE-9875150 and CHE-0110846 and a predoctoral fellowship to L.A.P., the Purdue Research Foundation (fellowships to H.C.C. and J.M.S.), the Indiana Instrumentation Institute (fellowship to L.A.P.), and the Sloan Foundation. J.M.B. is a Cottrell Teacher-Scholar of Research Corporation (2000 - 2002), and a Camille and Henry Dreyfus Teacher-Scholar (2002-2004). The Purdue Laboratory of Chemical Nanotechnology is acknowledged for technical support and expert advice. Professors Ralph G. Nuzzo and Fred E. Lytle are thanked for providing samples for microcontact printing. Dr. Richard T. Haasch is acknowledged for the acquisition of XPS data, carried out at the Center for Microanalysis of Materials, University of Illinois, which is partially supported by the U. S. Department of Energy under grant DEFG02-96-ER45439.

Supporting Information Available: Detailed experimental procedures for wafer treatment and noble metal film deposition along with additional micrographs and X-ray analysis. This material is available free of charge via the Internet at http://www.pubs.acs.org. 


\section{References}

(1) Xia, Y.; Rogers, J. A.; Paul, K. E.; Whitesides, G. M. Chem. Rev. 1999, 99, 1823.

(2) Piner, R. D.; Zhu, J.; Xu, F.; Hong, S.; Mirkin, C. A. Science 1999, 283,661 .

(3) Demers, L. M.; Park, S.-J.; Taton, T. A.; Li, Z.; Mirkin, C. A. Angew. Chem., Int. Ed. 2001, 40, 3071.

(4) Maynor, B. W.; Filocamo, S. F.; Grinstaff, M. W.; Liu, J. J. Am. Chem. Soc. 2002, 124, 522. Noy, A.; Miller, A. E.; Klare, J. E.; Weeks, B. L.; Woods, B. W.; DeYoreo, J. J. Nano Lett. 2002, 2, 109.

(5) Wilson, D. L.; Martin, R.; Hong, S.; Cronin-Golomb, M.; Mirkin, C. A.; Kaplan, D. L. Proc. Nat. Acad. Sci. U.S.A. 2001, 98, 13660

(6) Lee, K.-B.; Park, S.-J.; Mirkin, C. A.; Smith, J. C.; Mrksich, M. Science 2002, 295, 1702.

(7) Ivanisevic, A.; Mirkin, C. A. J. Am. Chem. Soc. 2001, 123, 7887.

(8) Wang, D.; Thomas, S. G.; Wang, K. L.; Xia, Y.; Whitesides, G. M. Appl. Phys. Lett. 1997, 70, 1593.

(9) Hidber, P. C.; Helbig, W.; Kim, E.; Whitesides, G. M. Langmuir 1996, 12, 1375

(10) Su, M.; Liu, X.; Li, S.-Y.; Dravid, V. P.; Mirkin, C. A. J. Am. Chem. Soc. 2002, 124, 1560.

(11) Kind, H.; Geissler, M.; Schmid, H.; Michel, B.; Kern, K.; Delamarche, E. Langmuir 2000, 16, 6367.

(12) Maynor, B. W.; Li, Y.; Liu, J. Langmuir 2001, 17, 2575.

(13) Porter, L. A., Jr.; Choi, H. C.; Ribbe, A. E.; Buriak, J. M. Nano Lett. 2002, 2, 1067.

(14) Zhang, X. G. Electrochemistry of Silicon and its Oxide; Kluwer: New York, 2001.

(15) Shipway, N.; Katz, E.; Willner, I. ChemPhysChem 2000, 1, 18.

(16) Penner, R. M. Acc. Chem. Res. 2000, 33, 78.

(17) Aiken, J. D.; Finke, R. G. J. Mol. Catal. A 1999, 145, 1.
(18) Zheng, J. W.; Li, X. W.; Gu, R. N.; Lu, T. H. J. Phys. Chem. B 2002, 106, 1019. Nie, S. M. Science 1997, 275, 1102.

(19) Twardowski, M.; Nuzzo, R. G. Langmuir 2002, 18, 5529.

(20) Oskam, G.; Long, J. G.; Natarajan, A.; Searson, P. C. J. Phys. D. 1998, 31, 1927.

(21) Gorostiza, P.; Kulandainathan, M. A.; Díaz, R.; Sanz, F.; Allongue, P.; Morante, J. R. J. Electrochem. Soc. 2000, 147, 1026.

(22) Zambelli, T.; Munford, M. L.; Pillier, F.; Bernard, M.-C.; Allongue, P. J. Electrochem. Soc. 2001, 148, C614.

(23) Takano, N.; Niwa, D.; Yamada, T.; Osaka, T. Electrochim. Acta 2000, 45, 3263.

(24) Gorostiza, P.; Díaz, R.; Sanz, F.; Morante, J. R. J. Electrochem. Soc. 1997, 144, 4119.

(25) Coulthard, I.; Sham, T. K. Solid State Commun. 1998, 105, 751.

(26) Zhu, Y. J.; Coulthard, I.; Sham, T. K. J. Synchrotron Rad. 1999, 6, 529.

(27) Süzer, S.; Dag, O. Can. J. Chem. 2000, 78, 516.

(28) Srinivasan, R.; Suni, I. I. Surf. Sci. 1998, 408, L698.

(29) Magagnin, L.; Maboudian, R.; Carraro, C. J. Phys. Chem. B 2002, 106, 401.

(30) Chyan, O. M. R.; Chen, J.-J.; Chien, H. Y.; Sees, J.; Hall, L. J. Electrochem. Soc. 1996, 143, 92.

(31) Yamada, T.; Takano, N.; Yamada, K.; Yoshitomi, S.; Inoue, T.; Osaka, T. Jpn. J. Appl. Phys. 2001, 40, 4845.

(32) Lee, T.; Liu, J.; Chen, N.-P.; Andres, R. P.; Janes, D. B.; Reifenberger, R. J. Nanoparticle Res. 2000, 2, 345.

(33) Choi, K.; Buriak, J. M. Langmuir 2000, 16, 7737.

(34) Wojtyk, J. T. C.; Tomietto, M.; Boukherroub, R.; Wayner, D. D. M. J. Am. Chem. Soc. 2001, 123, 1535.

(35) The solubility of $\mathrm{GeO}_{2}$ in cold water is $10 \mathrm{~g} / \mathrm{L}$. Glockling, F. The Chemistry of Germanium; Academic Press: London, 1969; p. 35.

NL025790K 